
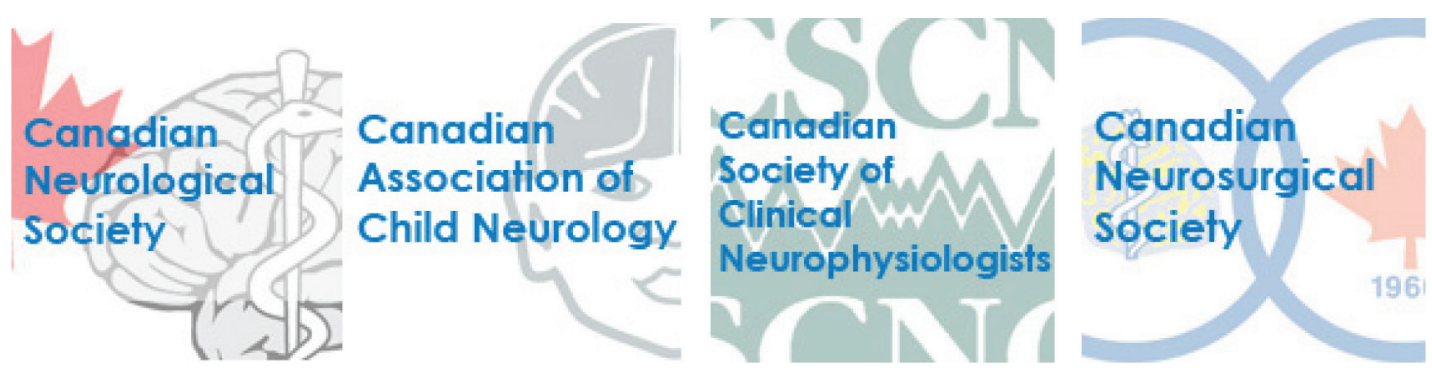

\title{
CNSF 2019 Society Prize Winners
}

\section{We are very pleased to announce this year's Society Prize Winners.}

\section{First place prize winners present at the Congress Grand Plenary Session on Monday June $17^{\text {th }}$ alongside our Grand Plenary Distinguished Guest Lecturers}

\author{
CNS - Francis McNaughton Memorial Prize - Adil Harroud \\ "Childhood obesity and multiple sclerosis susceptibility: a Mendelian randomization study" \\ CNS - Andre Barbeau Memorial Prize - Vincent Picher-Martel \\ "Neuronal expression of Ubiqulin-2 mutant exacerbates TDP-43 aggregation in ALS mouse mode" \\ CACN - The President's Prize - Michelle Chiu \\ "Prevalence and determinants of seizure action plans in a pediatric epilepsy population" \\ CSCN - Herbert Jasper Prize - Andrea Parks \\ "Diagnostic yield of Next Generation Sequencing and Myositis autoantibody panels in patients with Axial Myopathy" \\ CNSS - KG McKenzie Memorial Prize Clinical Research - Cameron Elliott \\ "Intraoperative acquisition of diffusion tensor imaging in cranial neurosurgery: readout-segmented DT1 versus standard single-shot DT1"
}

CNSS- KG McKenzie Memorial Prize Basic Research - Candice Poon

"Differential microglia and macrophage profiles in human IDH-mutant and-wildtype glioblastoma reveal therapeutic vulnerabilities"

\section{Supplementary Society Prize Awards}

CNS - Autoimmune Encephalitis

This year, the CNS was able to provide an additional opportunity for prize submission. In cooperation with the Anti-NMDA Receptor Encephalitis Foundation, they selected two prize winners for the best papers on Autoimmune Encephalitis. These winners will present their work during the CNSF Congress.

CNS - Autoimmune Encephalitis - Dhruv Jain

"Effects of REM sleep in anti-NMDA receptor encephalitis with extreme delta brush pattern"

CNS - Autoimmune Encephalitis - Aravind Ganesh

"Worldwide neurologist survey on management of autoimmune encephalitis"

CNSS has also awarded 2 - Second Place Prizes for the following Abstract Prize submissions. These winners will present their work at the CNSS Chairs Select Platform presentations on Wednesday morning, June $19^{\text {th }}$.

CNSS - KG McKenzie Memorial Prize Clinical Research - 2nd Prize - Ayoub Dakson

"A nation-wide prospective multi-centre study of external ventricular drainage accuracy, safety and related complications"

CNSS- KG McKenzie Memorial Prize Basic Research - 2nd Prize - Farshad Nassiri

"Predicting individualized risk of recurrence: development and validation of a DNA-methylation based nomogram in meningioma" 